\title{
Evaluation of central corneal thickness and corneal curvature in patients with rheumatoid arthritis
}

\author{
Rubina Huda1', Syed Ali Nasar Waris², Sankar Kumar T'3 , Panchapakesa Rajendran C ${ }^{4}$ \\ ${ }_{1,2}$ Associate Professor, ${ }^{3}$ Professor and Head, Department of Ophthalmology, ${ }^{4}$ Consultant Rheumatologist, Department \\ of Rheumatology, SRM Medical College and Hospital, Chennai, Tamil Nadu, India
}

Background: Rheumatoid arthritis is an autoimmune disease. It is a chronic disease that causes symmetrical deforming type of polyarthritis. Rheumatoid arthritis most commonly involves the anterior segment of the eye. It causes keratoconjunctivitis sicca, episcleritis, scleritis, sclerosing keratitis, stromal keratitis, paracentral keratolysis, and peripheral ulcerative keratitis. Aims and Objectives: The purpose of this study was to evaluate central corneal thickness (CCT) and corneal curvature in patients with rheumatoid arthritis. We also evaluated the association between CCT, corneal curvature, and rheumatoid arthritis severity. Materials and Methods: A total of 49 rheumatoid arthritis patients and 49 control subjects were enrolled in this study. The study was conducted in the ophthalmology department of SRM medical college, Chennai. A detailed ophthalmological examination was performed on each subject. Dry eye evaluation was done using Shirmers test, tear breakup time, and corneal fluorescein staining. The CCT and corneal curvature were measured by ultrasonic pachymetry and auto keratorefractometer, respectively. For statistical analysis, we used chi-square test, Fisher exact test, student t-test, and ANOVA test. Results: Mean CCT in all rheumatoid arthritis patient group eyes was $532.78 \pm 14.03$ micrometers. Mean CCT in rheumatoid arthritis with dry eye was $522.3 \pm 11.10$ micrometer, in rheumatoid arthritis without dry eye was $536.90 \pm 11.60$ micrometer and control patients' group was $564.80 \pm 20$ micrometer respectively. The difference of CCT was found to be statistically significant $(\mathrm{P}<0.05)$ between rheumatoid arthritis and control eyes. Mean corneal curvature was $42.71 \mathrm{D} \pm 2.16$ in all rheumatoid arthritis patients. Mean corneal curvature was 42.7D \pm 1.6 in rheumatoid arthritis with dry eye, $42.8 \mathrm{D} \pm 2.5$ in rheumatoid arthritis without dry eye, and $42.5 \mathrm{D} \pm 2.1$ in control eye, respectively. Our result did not show statistically significant difference in corneal curvature between the rheumatoid arthritis patients and control patients. CCT and corneal curvature were not associated with rheumatoid arthritis activity and rheumatoid arthritis duration. Conclusion: The CCT was thinner in rheumatoid arthritis patients than control patients. In order to improve the quality of vision of rheumatoid arthritis patients, we suggest including pachymetry as a routine ophthalmic examination in them. Pachymetry will be helpful in diagnosing and guiding clinical treatment in these patients.

Key words: Central corneal thickness; Corneal curvature; Dry eye; Rheumatoid arthritis
Access this article online

Website:

http://nepjol.info/index.php/AJMS

DOI: 10.3126/ajms.v13i2.40672

E-ISSN: 2091-0576

P-ISSN: 2467-9100

Copyright (c) 2022 Asian Journal of Medical Sciences

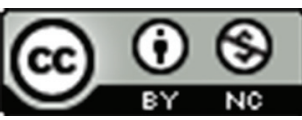

This work is licensed under a Creative Commons Attribution-NonCommercial 4.0 International License.

\section{INTRODUCTION}

Rheumatoid arthritis is an autoimmune disease. It is a chronic disease that causes symmetrical deforming type of polyarthritis. It can affect any joint. The most commonly involved joint is inter phalangeal joints. Rheumatoid arthritis most commonly involves the anterior segment of the eye. ${ }^{1}$ It causes keratoconjunctivitis sicca, episcleritis, scleritis, sclerosing keratitis, stromal keratitis, paracentral keratolysis, peripheral ulcerative keratitis. In rheumatoid arthritis, posterior segment findings are posterior scleritis and retinal vasculitis which are rare. 
Keratoconjunctivitis sicca is the most common ocular manifestation of rheumatoid arthritis. Almost $25 \%$ of patients with rheumatoid arthritis are affected with keratoconjunctivitis sicca. ${ }^{2}$ Whenever keratoconjunctivitis sicca is seen along with xerostomia and autoimmune disease such as rheumatoid arthritis, it is classified as Secondary Sjogrens syndrome. If there is an autoimmune involvement of the lacrimal glands, it leads to an aqueous tear deficiency causing Dry Eye Syndrome clinically.

In order to have an appropriate anterior refractive surface and to protect the eye from infection, we need a healthy cornea along with an overlying tear film. Corneal epithelium mainly consists of 4-6 cell layers of squamous cells. ${ }^{3} \mathrm{It}$ is non-keratinized stratified squamous epithelium. A tear film covers the corneal epithelium. The tear air interface along with the cornea accounts for two-thirds of total refractive power of the eye. In order to promote the spreading of tear film with every eye blink, the mucin part of the tears acts intimately with the glycol-calyx of the cornea epithelial cells. The tear film also guards the corneal epithelium from infection in addition from any kind of chemical or even toxic injury. In this way, we can say that corneal epithelium and ocular surface tear film have a close relationship. ${ }^{4}$

Dry Eye Disease or keratoconjunctivitis sicca is because of decreased tear production, increased tear evaporation, or sometimes both. The tear film consists of three layers. ${ }^{5}$ The innermost layer is the mucin layer. It is secreted by the goblet cells of the conjunctiva. It sticks to mainly to the glycoprotein on the surface of the corneal epithelium. As it is hydrophilic in nature, it is able to make a wet surface on the corneal epithelium. The aqueous layer form the middle layer. It is secreted by lacrimal glands. The lipid layer, which is secreted by the meibomian gland, prevents the evaporation of tears.

Dry eye syndrome consists of ocular irritation and visual disturbances due to changes in tear film and ocular surface. The result of Dry eye syndrome can lead to minor difficulty to alarming sight-threatening complications. The 2017 report from the International Dry Eye Workshop, TFOS DEWS II has defined dry eye as a disease which is multifactorial in origin. ${ }^{6}$ It is a disease of tears and ocular surface that often leads to eye discomfort, visual disturbance, and instability of tear film. It is characterized by a loss of hemostasis of the tear film, tear film hyperosmolarity, ocular surface inflammation, and damage. Neurosensory abnormalities also have an etiological role to play.

Although different causes are there for dry eye, they have similar symptoms such as itchin, burning, foreign body sensation, dryness, ocular fatigue, and redness. Signs include conjunctival injection, decreased tear meniscus, photophobia, increased tear debris, and loss of corneal luster seen mostly in the exposed inter palpebral fissure.

When we measure the corneal thickness, it is called pachymetry. Measurement of central corneal thickness (CCT) and corneal curvature plays an important role before keratorefractive surgeries. CCT measurement is helpful in diagnosing and management of glaucoma and keratoconus. The evaluation of CCT helps us in accurate determination of intraocular pressure. ${ }^{7}$ CCT can be useful in predicting the survival of the corneal graft. ${ }^{8}$ The average CCT is 540 micrometer. There are various tools to measure CCT. Ultrasound pachymetry, which we have used in our study, measures the CCT from the tear film to the posterior aspect of the endothelium., ${ }^{910}$ Very few studies, in developing world, have been done to examine CCT and corneal curvature in patients with rheumatoid arthritis, although rheumatoid arthritis mainly affects the cornea and ocular surface. ${ }^{11,12}$

\section{Aims and objectives}

The purpose of this study was to evaluate central corneal thickness (CCT) and corneal curvature in patients with rheumatoid arthritis. We also evaluated the correlations between central corneal thickness, corneal curvature, and rheumatoid arthritis activity and duration.

\section{MATERIALS AND METHODS}

The study was conducted in ophthalmology outpatient department of SRM Medical College Hospital. 49 patients (98 eyes) with rheumatoid arthritis, who were referred from the rheumatology department of SRM medical college and hospital to ophthalmology department, and 49 age and gender-matched healthy control patients (98 eyes) were included in our study. Patients with active corneal infection, glaucoma, contact lens wearer, previous eye laser, eye surgery, and trauma, or any use of topical eye drugs were excluded from our study. The presence of any systemic disease except rheumatoid arthritis was also excluded from the study. Duration of this study was 1 year, from June 2019 to May 2020. The study was approved from the ethical committee of SRM Medical College and hospital.

All subjects in our study underwent the required ophthalmological examination. We recorded the uncorrected and best-corrected visual acuity and intraocular pressure. With the help of a slit lamp biomicroscopy, complete anterior segment examination was done. We gave a questionnaire of the ocular surface disease index to our patients before doing the ophthalmic examination. ${ }^{13}$ 
Dry eye has been defined as having eye discomfort in patients who had at least two abnormal diagnostic test values

Tear Breakup time (TBUT) of $<10 \mathrm{~s}$

Corneal fluorescein staining score $\geq 1^{14}$

Schirmer's 1 test value of $\leq 10 \mathrm{~mm}$

TBUT test was performed with a sterile fluorescein strip. The strip was placed in the lower eyelid fornix. The subject was asked to blink three times and then look straight forward without blinking. The time interval between a complete blink and first appearance of a dry spot on the pre-corneal tear film was measure under cobalt blue filtered light. The mean of three consecutive TBUT measurements was used for analysis. Two spots in $<10 \mathrm{~s}$ were considered abnormal. After recording TBUT measurement; corneal fluorescein staining was evaluated by Van Bijsterveld scoring system.

In the Schirmers test, the round edge of the Schirmer strip was placed behind between the outer and middle third of the eyelid. After a gap of $5 \mathrm{~min}$, the strip was removed and the wet portion of the strip was measured in millimeters. Patients who had a Schirmers test score $\leq 10 \mathrm{~mm} / 5 \mathrm{~min}$ were considered to have dry eye. During the test, the patients should be sitting comfortably.

The corneal curvature measurements were taken using an auto refractometer (Canon RK-F2, Japan). Measurement of CCT was performed $10 \mathrm{~min}$ after completing dry eye test. CCT was measured with an ultrasonic pachymeter (Appascan MAX P, Appaswamy, India), after putting a drop of propacaine hydrochloride $0.5 \%$ for topical anesthesia. The probe tip of the pachymeter was placed perpendicular to the cornea of the subject and kept at the center of the cornea. We took six consecutive measurements into account and out of six, only the three lowest measurements were averaged.

We did an evaluation of the disease activity and quality of life also; it was done on the same day as the ocular examinations. The disease activity was assessed using the Disease activity index-28 (DAS-28), while assessing it we used DAS-28 online calculator of the American College of rheumatology with respect to the number of tender and swollen joints, C-reactive protein level, and the global health assessment of patients using scale. ${ }^{15}$ We used Health assessment questionnaire to access the quality of life of our patients. This questionnaire includes questions in eight headings; dressing, rising, eating, walking, hygiene, reach, grip, and usual activities. Each question is answered on a four-grade scale of impairment ranging from 0 to 3; 0 -no difficulty.1-some difficulty, 2-much difficulty, 3-inability to do so. The laboratory evaluation tested the erythrocytes sedimentation rate and C-reactive protein.

\section{Statistical methods}

Data were entered in MS Excel sheet and analyzed using SPSS software version 21. Continuous variables were represented in mean and standard deviation. Categorical variables were represented in frequencies and percentages. When a categorical Variable is associated with a categorical variable, the significance is tested using Chi-square test. Fishers exact test is used when more than $20 \%$ of the cell value $<5$. When a continuous variable is associated with a categorical variable the variables were represented by mean ( \pm standard deviation) in tables and the significance of the difference between the means is tested by Student t-test for two categories and ANOVA test for more than three categories. $\mathrm{P}<0.05$ were considered statistically significant.

\section{Ethics approval and informed consent}

This study was carried out after approval from SRM Medical College and Hospital Ethical committee (27 June 2019). The study followed the declaration of Helsinki for medical research involving human subjects. Informed consent was obtained from the patients.

\section{RESULTS}

The mean age among rheumatoid arthritis group was 56.27 which is higher than mean age among control group which was 52.88 and the difference was not statistically significant. Considering the gender of the subjects with rheumatoid arthritis distribution, there was no difference in gender distribution between rheumatoid arthritis group and control group. The mean corneal curvature among rheumatoid arthritis was $42.71 \mathrm{D}$ $( \pm 2.16 \mathrm{D})$ which is higher than mean corneal curvature among controls which was $42.53 \mathrm{D}( \pm 2.06 \mathrm{D})$ but the difference was not statistically significant. The mean CCT among rheumatoid arthritis was 532.78 micrometer $( \pm 14.03)$ which is lower than the mean central corneal

\begin{tabular}{|c|c|c|c|}
\hline & \multicolumn{2}{|c|}{ Group } & \multirow{2}{*}{$\begin{array}{c}P \\
\text { value }\end{array}$} \\
\hline & RA & CONTROL & \\
\hline Age (years) & $56.3( \pm 11.6)$ & $52.9( \pm 8.9)$ & 0.108 \\
\hline \multicolumn{4}{|l|}{ Gender } \\
\hline Males & $28(57.1 \%)$ & $31(63.3 \%)$ & 0.536 \\
\hline Females & $21(42.9 \%)$ & $18(36.7 \%)$ & \\
\hline $\begin{array}{l}\text { Corneal } \\
\text { Curvature } \\
\text { (Diopter) }\end{array}$ & $42.71 \mathrm{D}( \pm 2.16)$ & $42.53 \mathrm{D}( \pm 2.06)$ & $0.668^{\#}$ \\
\hline $\begin{array}{l}\text { СCT } \\
\text { (micrometer) }\end{array}$ & $532.78( \pm 14.03)$ & $564.76( \pm 19.95)$ & $0.001^{\#}$ \\
\hline
\end{tabular}


curvature among control which was 564.76 micrometer $( \pm 19.95)$ and the difference was statistically significant, as shown in Table 1.

Mean rheumatoid arthritis duration was 146.47 ( \pm 53.22$)$ months ranging from 35 to 235 months. Mean disease severity score was $4.17 \pm 1.06$ ranging from 2.7 to 6.7 . In our study, CCT and corneal curvature were not associated with disease activity score and rheumatoid arthritis duration. Mean Erythrocyte sedimentation rate was $39.45 \pm 6.21$ millimeter per hour. Mean C-reactive protein was $4.63 \pm 2.01$ ranging from 2 to 9 milligram per liter.

The mean corneal curvature among rheumatoid arthritis without dry eye was $42.76 \mathrm{D}$ which is higher than mean corneal curvature among rheumatoid arthritis with dry eye which was $42.65 \mathrm{D}$ followed by Controls with a mean of $42.53 \mathrm{D}$, but the difference was not statistically significant $(\mathrm{P}>0.05)$.

The mean CCT among controls was 564.76 micrometer which is higher than mean CCT among rheumatoid arthritis with dry eye which was 522.3 micrometer followed by rheumatoid arthritis without dry eye with a mean of 536.9 micrometer and the difference was statistically significant $(\mathrm{P}<0.05)$, as shown in Table 2.

\section{DISCUSSION}

Rheumatoid arthritis is one of the most common inflammatory arthritis. Approximately $40 \%$ of the patients with rheumatoid arthritis have extra-articular involvement. In the eye, the most common ocular involvement is manifested as dry eye in about $25 \%$ of the patients. ${ }^{16,17} \mathrm{It}$ can also involve the sclera, cornea, and uvea. Rheumatoid arthritis mainly involves the anterior segment.

Various studies have reported that an increase in cytokines activates corneal cells to produce proteolytic enzymes which cause degradation of extracellular matrix..$^{18}$ Hence, this process of collagenolysis in rheumatoid arthritisrelated corneal inflammation could have an influence on CCT and corneal curvature values. Villani et al., found that CCT was significantly thinner in patients with rheumatoid arthritis, with or without secondary Sjogren syndrome than in healthy subjects. ${ }^{19}$ In their study, corneal thickness of rheumatoid arthritis patients with secondary Sjogren was 514.75 micrometer and was 559.23 micrometer in control group.

In our study, there was a statistically significant difference in CCT between controls and rheumatoid arthritis patients. We did not get any statistically significant difference in corneal curvature between the control group and rheumatoid arthritis patients.

Prata et al., did a study to evaluate corneal hysteresis and CCT in patients with rheumatoid arthritis and in agematched controls. ${ }^{20}$ They found an abnormal corneal biomechanics in patients with rheumatoid arthritis. They reported that CCT was slightly thinner (520.2 vs. 534.9 micrometer) in patients with rheumatoid arthritis than in controls but the difference was not statistically significant, unlike our study.

Tuominen et al., in their study reported that the corneal epithelium was irregular and patchy in secondry Sjogren's syndrome patients. ${ }^{21}$ They even reported that the central corneal thickness was decreased because of stromal thinning. According to their study, the pump and barrier function of the epithelium, as well as endothelium, were responsible mainly of corneal thickness. Hence, a defective barrier function of the epithelium and endothelium results in corneal dehydration and thinning.

$\mathrm{Xu}$ et al., reported that in secondary Sjogren-related dry eye, there is a decreased corneal sensitivity. ${ }^{22}$ It is a known fact that an intact corneal innervation is quite essential for normal blinking and even tearing reflexes. A poor blinking reflex may result in ocular surface disease.

Yeh et al., reported in their study that increased production of inflammatory and catabolic cytokines, such as tumor necrosis factor-alpha and interleukin 1 (IL-1) were responsible for central thinning. ${ }^{23}$ Liu and Pflugfelder in their study said that various factors contribute to decreased corneal thickness in dry eyes. ${ }^{24}$ According to their study, the chronically stressed out corneal epithelium releases IL-1. Increased levels of inflammatory cytokines in dry eye, such as IL-1, lead to

\begin{tabular}{|c|c|c|c|c|}
\hline \multirow[t]{2}{*}{ Variable } & \multicolumn{3}{|c|}{ Group } & \multirow[t]{2}{*}{ ANOVA $P$ value } \\
\hline & RA with dry eye & RA without dry eye & Control & \\
\hline Corneal curvature (Diopter) & 42.7D $( \pm 1.6)$ & $42.8 \mathrm{D}( \pm 2.5)$ & $42.5 \mathrm{D}( \pm 2.1)$ & 0.898 \\
\hline CCT (micrometer) & $522.3( \pm 11.1)$ & $536.9( \pm 11.6)$ & $564.8( \pm 20)$ & 0.001 \\
\hline
\end{tabular}


more matrix degradation. They also reported that corneal thinning may be because of an increased osmolarity of tear film due to tear film evaporation. Another reason that they cited in their study was decreased tear film thickness. According to them, there was a reduced mucus production by decreased ocular surface epithelium. This is similar to our findings where there is also significant difference in CCT between control and RA eyes with or without dry eye.

\section{Limitations of the study}

Our study has few limitations. This was a cross sectional study with a relative small sample size. These findings need to be confirmed in future studies.

\section{CONCLUSION}

Rheumatoid arthritis is known to affect the cornea and ocular surface. In order to improve the quality of vision of rheumatoid arthritis patients, we suggest including pachymetry as a routine ophthalmic examination in them. Pachymetry will be helpful in diagnosing and guiding clinical treatment in these patients. Further research may be needed for a better understanding of cornea in rheumatoid arthritis patients.

\section{ACKNOWLEDGMENT}

The authors acknowledge the support of the Rheumatology Department for this study.

\section{REFERENCES}

1. Harper SL and Foster CS. The ocular manifestations of rheumatoid disease. Int Ophthalmol Clin. 1998;38(1):1-19. https://doi.org/10.1097/00004397-199803810-00003

2. Thompson $\mathrm{M}$ and Eadie S. Kerato-conjunctivitis sicca and rheumatoid arthritis. Ann Rheum Dis. 1956;15:21-25. https://doi.org/10.1136/ard.15.1.21

3. Bowling B. Dry Eye, Kanski's Clinical Ophthalmology: A Systematic Approach. $8^{\text {th }}$ ed. China: Elsevier Group; 2016. p. 120.

4. Yanoff M, Duker J. Ophthalmology. $4^{\text {th }}$ ed. Amsterdam, Netherlands: Elsevier Group; 2014. p. 274.

https://doi.org/10.5005/jp/books/12179_81

5. Holly FJ and Lemp MA. Tear physiology and dry eyes. Surv Ophthalmol. 1997;22(2):69-87. https://doi.org/10.1016/0039-6257(77)90087-X

6. Craig JP, Nichols KK, Akpek EK, Caffery B, Dua HS, Joo CK, et al. TFOS DEWS II definition and classification report. Ocul Surf. 2017;15(3):276-283.

https://doi.org/10.1016/j.jtos.2017.05.008

7. Gordon MO, Beiser JA, Brandt JD, Heuer DK, Higginbotham EJ, Johnson CA, et al. the ocular hypertension treatment study groups, The ocular hypertension treatment study; baseline factors that predict the onset of primary open angle glaucoma. Arch Ophthalmol. 2002;120(6):714-720.

https://doi.org/10.1001/archopht.120.6.714

8. Verdier DD, Sugar A, Baratz K, Beck R, Dontchev M, Dunn S, et al. Corneal thickness as a predictor of corneal transplant outcome. Cornea. 2013;32(6):729-736. https://doi.org/10.1097/ICO.0b013e31827b14c7

9. Lackner B, Schmidinger G, Pieh S, Funovics MA and Skorpik C. Repeatability and reproducibility of central corneal thickness measurement with pentacam, orbscan, and ultrasound. Optom Vis Sci. 2005;82(10):892-898.

https://doi.org/10.1097/01.opx.0000180817.46312.0a

10. Celebi AR and Mirza GE. Differences in central corneal thickness between spectral domain-optical coherence tomography and ultrasound pachymetry in patients with dry eye disease. J Ophthalmol. 2016;2016:2623719. https://doi.org/10.1155/2016/2623719

11. Hovding G. The central corneal thickness in keratoconjunctivitis sicca. Acta Ophthalmol (Copenh). 1992;70(1):108-110. https://doi.org/10.1111/j.1755-3768.1992.tb02100.x

12. Sanchis-Gimeno JA, Lleo-Perez A, Alonso L, Rahhal MS and Martinez-Soriano F. Reduced corneal thickness values in postmenopausal women with dry eye. Cornea. 2005;24(1):39-44.

https://doi.org/10.1097/01.ico.0000138836.45070.0f

13. Ozcura F, Aydin S and Helvaci MR. Ocular surface disease index for the diagnosis of dry eye syndrome. Ocul Immunol Inflamm. 2007; 15(5):389-393.

https://doi.org/10.1080/09273940701486803

14. Van Bijsterveld OP. Diagnosis and differential diagnosis of keratoconjunctivitis sicca associated with tear gland degeneration. Clin Exp Rheumatol. 1990;8(Suppl 5):3-6.

15. Fransen $\mathrm{J}$ and Van Riel PL. The disease activity score and the EULAR response criteria. Clin Exp Rheumatol. 2005;23(5 Suppl 39):93-9.

16. Turesson C, O'Fallon WM, Crowson CS, Gabriel SE and Matteson EL. Extra-articular disease manifestations in rheumatoid arthritis: Incidence trends and risk factors over 46 years. Ann Rheum Dis. 2003;62(8):722-727. https://doi.org/10.1136/ard.62.8.722

17. Myasoedova E, Crowson CS, Turesson C, Gabriel SE, Matteson EL. Incidence of extraarticular rheumatoid arthritis in Olmsted County, Minnesota, in 1995-2007 versus 1985-1994: A population-based study. J Rheumatol. 2011;38(6):983-989.

https://doi.org/10.3899/jrheum.101133

18. Riley GP, Harrall RL, Watson PG, Cawston TE and Hazleman BL. Collagenase (MMP-1) and TIMP-1 in destructive corneal disease associated with rheumatoid arthritis. Eye. 1995;9(Pt 6):703-718. https://doi.org/10.1038/eye.1995.182

19. Villani E, Galimberti D, Viola F, Mapelli C, Del Papa N and Ratiglia R. Corneal involvement in rheumatoid arthritis: An in vivo confocal study. Invest Ophthalmol Vis Sci. 2008;49(2):560-564. https://doi.org/10.1167/iovs.07-0893

20. Prata TS, Sousa AK and Filho CA. Assessment of corneal biomechanical properties and intraocular pressure in patients with rheumatoid arthritis. Can J Ophthalmol. 2009;44(5):602 https://doi.org/10.3129/i09-082

21. Tuominen IS, Konttinen YT, Vesaluoma MH, Moilanen JA, Helinto $\mathrm{M}$ and Tervo TM. Corneal innervation and morphology 
in primary Sjogren's Syndrome. Invest Ophthalmol Vis Sci. 2003;44(6):2545-2549.

https://doi.org/10.1167/iovs.02-1260

22. $\mathrm{Xu} \mathrm{KP}$, Yagi $\mathrm{Y}$ and Tsubota $\mathrm{K}$. Decrease in corneal sensitivity and change in tear function in dry eye. Cornea. 1996;15(3):235-239.

https://doi.org/10.1097/00003226-199605000-00002
23. Yeh S, Song XJ, Farley W, Li DQ, Stern ME and Pflug-felder SC. Apoptosis of ocular surface cells in experimentally induced dry eye. Invest Ophthalmol Vis Sci. 2003;44(1):124-129. https://doi.org/10.1167/iovs.02-0581

24. Liu Z and Pflugfelder SC. Corneal thickness is reduced in dry eye. Cornea. 1999;18(4):403-407. https://doi.org/10.1097/00003226-199907000-00002

\section{Authors Contribution:}

RH- Data acquisition, Concept and Design. Collection of data and analysis; SANW-Participated in acquisition of data and drafting the manuscript, participated in data collection and statistical analysis, Interpretation and manuscript editing and manuscript review; SKT-Literature review, data analysis and interpretation;

PRC-Definition of intellectual content, data acquisition, data collection.

Work attributed to:

Department of Ophthalmology and Department of Rheumatology, SRM Medical College and Hospital, Chennai, Tamil Nadu, India

Orcid ID:

Dr. Rubina Huda - (10 https://orcid.org/0000-0002-6694-1204

Dr. Syed Ali Nasar Waris - (D) https://orcid.org/0000-0002-1178-9006

Dr. Shankar Kumar T - (i) https://orcid.org/0000-0003-4525-8884

Dr. Panchapakesa Rajendran C - (1) https://orcid.org/0000-0002-4520-8425

Source of Funding: None, Conflicts of Interest: None. 